sucheı, um feststellen zu können, ob dieser tatsächlich einen eklatanten therapeutischen Erfolg besitzt, oder ob meine Fälle dem bloßen post hoc zuzuschreiben sind.

Aus der Geburtshilflich-gynäkologischen Abteilung des Allgemeinen Krankenhauses in Ujvidék.

\title{
Zwei Fälle von Eklampsie geheilt mit Hypophysenextrakt.
}

\author{
Von Dr. Alexander Schossberger.
}

Zur Vervollständigung der konservativen Methoden in der Behaudlung der Elklampsie möchte ich zwei Fälle mitteilen, in denen das Hypophysenextrakt vorzügliche Wirkung hatte. Eklampsie ist in unserer Gegend verhältnismäßig selten, sodaß ich im Laufe des letzten Jahres nur die beschriebenen zwei Fälle beobachten konnte. Ich verwendete das Pituglandol La Roche.

Fall 1. P. V., 42 Jahre alt. V-para. 19. November nachts 1 Uhr: Patientin vollkommen bewußtlos. Gesicht stark zyanotisch. Gravid am Ende der normalen Schwangerschaft. Eklamptische Anfälle kontinuierlich, keine Pausen. Muttermund geschlossen. 5\% Albumen. Kochsalzgehalt des Urins vermilldert. Sofort Injektion von 1,1 Pituglandol und gleichzeitig 0,02 Pantopon. Anfälle sistieren nach einer halben Stunde. 4 Uhr morgens kehrt Bewußtsein zurück, Muttermund für einen Finger durchgängig. Zweite Pituglandolinjektion. 6 Uhr morgens glatte Entbindung eines gesunden Knaben. Plazenta nach fünf Minuten. Patientin vollkommen genesen. Nach Monaten noch Spuren von Albumen.

Fall 2. M. Cs., 23 Jahre alt. II-para. Gravid im sechsten Monat. 22. März 11 Uhr nachts. BewuBtlosigkeit; eklamptische Anfälle unaufhörlich. Gesicht gedunsen, untere Extremitäten ödematös. Puls 140, klein. Anurie. Muttermund geschlossen. Injektion 1,1 Pituglandol und 0,02 Pantopon. Innerlich Digitalis + Diuretin, wird jedoch sofort erbrochen. Nach 3/4 Stunden Aussetzen der eklamptischen Anfälle. $2 \mathrm{Chr}$ nachts Muttermund für den kleinen Finger durchgängig. Diurese tritt ein.. Im Urin reichlich Albumen, Kochsalzgehalt 0,1. Zweite Pituglandolinjektion. - $4 \mathrm{Uhr}$ morgens wird der sechsmonatige Foetus lebend geboren und beinahe gleichzeitig die Plazenta. Foetus verscheidet nach 15 Minuten. Patientin nach acht Tagen vollkommen hergestellt. Nach vier Wochen schwinden die letzten Spuren von Albumen.

Ich würde den Vorschlag nlachen, in den konservativ zu behandelnden Fällen von Eklampsie jedesmal Hypophysenextrakt zu ver- 